Copyright ( $) 2019$ University of Bucharest Printed in Romania. All rights reserved

ISSN print: $1224-5984$

ISSN online: $2248-3942$
Rom Biotechnol Lett. 2019; 24(6): 1067-1074 doi: $10.25083 / \mathrm{rbl} / 24.6 / 1067.1074$

Received for publication, November, 30, 2017

Accepted, October, 1, 2018

Original paper

\title{
Influence on retention improvement of fiber posts by surface conditioning in vitro study
}

LUMINITAA OANCEA ${ }^{1}$, DANIELA NICU ${ }^{2}$, ALEXANDRU PETRE ${ }^{1}$, MIHAI BURLIBASA ${ }^{*}$, VIOREL ȘTEFAN PERIEANU ${ }^{1}$, MĂDĂLINA VIOLETA PERIEANU ${ }^{1}$, CARMEN DOMNARIU ${ }^{3}$, CAMELIA IONESCU ${ }^{1}$, MIHAELA ROMANIȚA GLIGOR ${ }^{3}$, RADU COSTEA ${ }^{1}$, MĂDĂLINA ADRIANA MALIȚA ${ }^{1}$, MIHAI DAVID ${ }^{1}$, NARCIS MARCOV ${ }^{1}$, BOGDAN PAVĂL ${ }^{2}$, GABRIELA TĂNASE ${ }^{1}$, ANDREEA ANGELA ȘTEȚIU ${ }^{3}$, CORINA MARILENA CRISTACHE ${ }^{1}$, ILEANA IONESCU ${ }^{1}$

1"Carol Davila" University of Medicine and Pharmacy Bucharest, Romania

${ }^{2}$ Private Dental Office, Bucharest, Romania

3"Lucian Blaga" University, Sibiu, Romania

\begin{abstract}
Purpose of the study: The aim of the study is to assess the influence of surface conditioning of fiberglass posts through etching and sandblasting, on retention to root canal.

Material and method: 30 maxillary single root teeth were endodontic treated and were sectioned at $2 \mathrm{~mm}$ from enamel-dentine junction. After root canal instrumentation, fiberglass posts with same length were adhesively cemented. Tooth-post assembly mounted in a special conformer, was loaded by a universal testing machine, recording the force and displacement at which the post is dislocated first. Data has been statistically analyzed.

Results: In the experimental group where posts were acid engraved samples yielded on greater forces $(117.75 \mathrm{~N})$ then group with sand blasted posts $(101 \mathrm{~N})$, but lower than the control group (129.36 N). Differences between the groups analyzed using ANOVA test, are not statistically significant.

Conclusions: The displacements phenomenon at the interfaces dentin-adhesive-post is not significantly influenced by the type of treatment of the posts surface, compared to the control group.
\end{abstract}

Keywords Fiberglass, canal instrumentation, retention.

To cite this article: OANCEA L, NICU D, PETRE A, BURLIBAȘA M, PERIEANU VȘ, PERIEANU MV, DOMNARIU C, IONESCU C, GLIGOR MR, COSTEA R, MALIȚA MA, DAVID M, MARCOV N, PAVĂL B, TĂNASE G, ȘTEȚIU AA, CRISTACHE CM, IONESCU I. Influence on retention improvement of fiber posts by surface conditioning in vitro study. Rom Biotechnol Lett. 2019; 24(6): 1067-1074. DOI: 10.25083/rbl/24.6/1067.1074 


\section{Introduction}

Retention improving of fiberglass posts was a constant concern of dental practitioners and researchers. Studies from scientific literature have identified as factors that influence the retention quality of fiberglass posts to the dental structures, the following: the length of post (STOCKTON, STANDLEE \& al, NERGIZ \& al [1-3]), the design, the diameter (STOCKTON, STANDLEE \& al, NERGIZ \& al, COHEN BI \& al [1-4]) and the type of cement used (ROSIN \& al, MENDOZA \& al $[6,7]$ ).

The surface treatment of the post is a clinical stage mentioned in most cementing protocols of fiberglass posts, indicated by manufacturing companies. However, this is still a quite controversial subject, still in the "gray area" of the scientific evidence, the results of research regarding the supremacy of one of conditioning method, being inconsistent. Conditioning treatments types of fiberglass posts used in different studies were silanization, acid etching, sandblasting and tribochimic treatment. After conducting experiments and drawing up statistical analyzes is generally observed that the higher values of adhesive strength, were recorded especially for acid etching and then sandblasting. The pre-treatment made by silanization, it has proven to be an ineffective method (BALBOSH \& al, CHOI \& al, SAHINKESEN \& al, PERDIGAÕ \& al [8-11]), which does not influence the adhesive strength particularly. The combination of acid engraving with a silane agent resulted in low values of adhesive strength (CHOI \& al., SAHINKESEN \& al, PERDIGAÕ \& al, SUMITHA \& al [9, 12]). In the case of tribochimic treatment, reports are contradictory - from increasing resistance to displacement (SCHMAGE \& al [13]) at no influence on retention (SAHAFI \& al [14]).
The studies in which pretreatment involved the conditioning by etching (SUMITHA \& al., SCHMAGE \& al, OHLMANN \& al, YENISEY \& al, ZAKEREYYA \& al $[12,13,15-17])$ phosphoric acid, fluoride acid, potassium permanganate and hydrogen peroxide were used. The values of adhesive strength at the time of displacement have varied depending on the acid used. High values were recorded for etching with hydrofluoric acid. Sandblasting has been mentioned in numerous experiments as a positive factor influencing the fixation of fiberglass posts (OHLMANN \& al., YENISEY \& al, ZAKEREYYA \& al [15-17]).

However, it was noticed the fact that the adhesive strengths were identical or slightly increased in control groups compared to groups of surface pretreatments. The adhesive strength stability in time was improved after acid etching and sandblasting (BALBOSH \& al, CHOI \& al, SUMITHA \& al, SCHMAGE \& al, SAHAFI \& al, OHLMANN \& al, YENISEY \& al, ZAKEREYYA \& al $[8,9,12-17])$.

In our study, we intend to evaluate the influence on quality of root retention after conditioning the surface of fiberglass posts by etching and sandblasting.

\section{Materials and Methods}

We have selected a number of 30 extracted single root upper teeth, of which 18 central incisors and 12 canines after following criteria: single root maxillary teeth without root fractures without carious processes extended at root level and without root resorption. Before preparation for the experiment, teeth were stored in saline solution at room temperature. The first intervention on the teeth was debridement of ligament tissue and creating entrance cavities for endodontic treatment. Root canal instrumentation was performed by Step-back technique (Fig. 1)
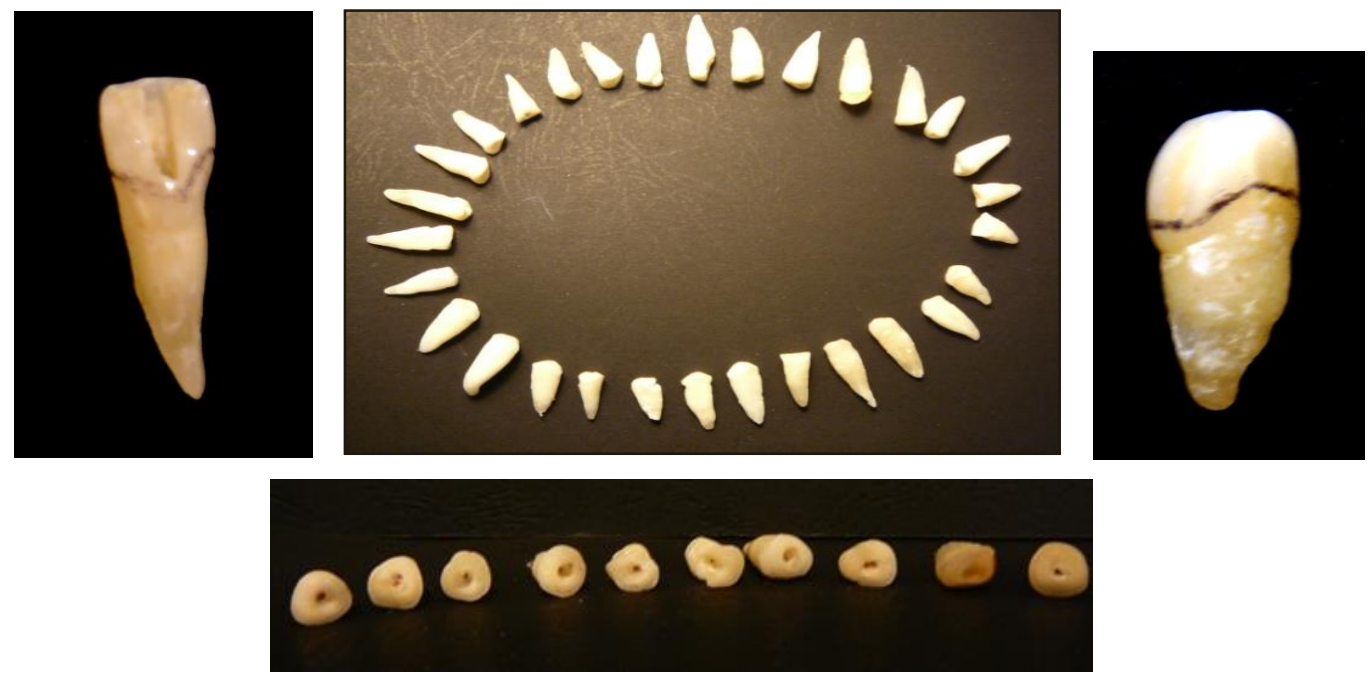

Figure 1. A total of 30 single root teeth selected for research (enamel-cementum junction sectioning phase) 
Lowest root length was $13.89 \mathrm{~mm}$ of an upper central incisor and the largest root length was $23.82 \mathrm{~mm}$ of an upper canine. Since the smallest root length is about $14 \mathrm{~mm}$, we have decreased $5 \mathrm{~mm}$ from root obturation size at apical end and thus it was determined that the space reserved for fiberglass posts was $9 \mathrm{~mm}(7 \mathrm{~mm}$ intraradicular and $2 \mathrm{~mm}$ external rod). Next stage was removing of root canal filling material. The removal of filling material, the paste and gutta-percha cones was performed using a heated fingerspreader, keeping $5 \mathrm{~mm}$ of the filling at apical level. Subsequently it was measured a distance of $2 \mathrm{~mm}$ from enamel-cementum junction, on all four tooth sides in order to achieve uniform external rod.

Dental crowns were sectioned respecting coronary substance outstanding size (external rod) of $2 \mathrm{~mm}$ with a cylindrical turbine bur, under cooling. After the sectioning, obtained root lengths were electronically measured using a caliper.

Fiberglass posts used in the experiment were chosen according to mesiodistal diameter of the tooth, with adequate diameters $1.2 \mathrm{~mm}$ and $1.8 \mathrm{~mm}$. Cavities in roots were prepared for fiberglass posts, using endodontic burs with adequate diameters for applied posts. Root preparation was performed by setting the working length - to $5 \mathrm{~mm}$ from the apex - under saline solution irrigation. The length of the glass fiber posts was standardized to $12 \mathrm{~mm}$ (inside tooth length of $9 \mathrm{~mm}$, and $3 \mathrm{~mm}$ for anchoring in testing device). In addition, the $3 \mathrm{~mm}$ have standardization role of curing distance from cervical area. Luting of fiberglss posts was performed using a resin cement, self-adhesive, self-etching and dual setting (self-curable and photopolymerizable).

Depending on the treatments applied before luting of posts, three experimental groups resulted:

- Control group (fiberglass posts are not surface conditioned) - Group C;

- Group with etched surface fiberglass posts $(37 \%$ phosphoric acid for 15 seconds) - Group G;

- Group with sandblasted fiberglass posts (aluminum oxide particles $50 \mu \mathrm{m}$ ) - Group $\mathrm{S}$.
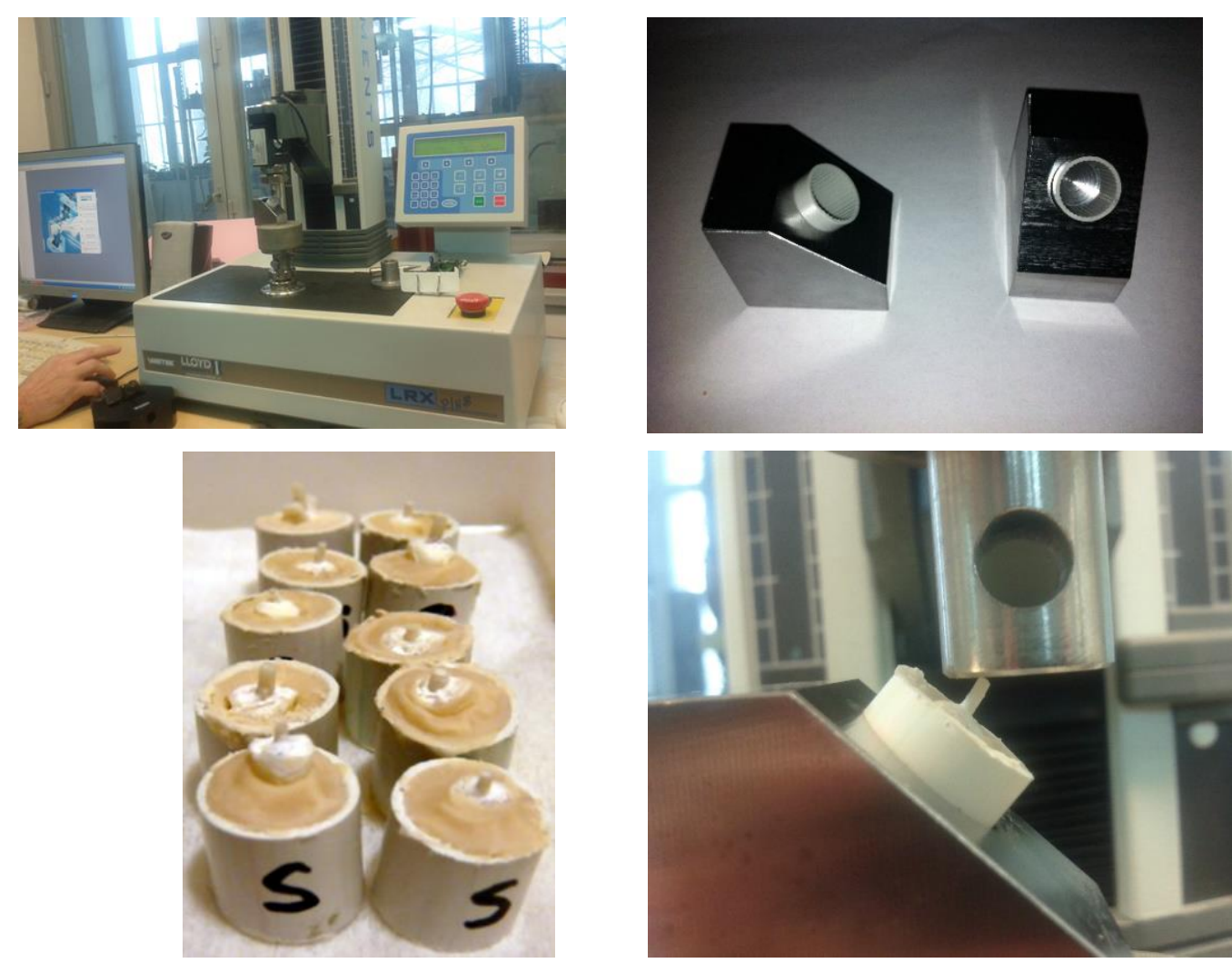

Figure 2. Creating mechanical load on tooth-luting cement-post using an universal testing machine

In order to apply stress on teeth with universal testing machine, they were prepared, as follows:

- A steel support was realized, with a circular cavity;

- In the cavity is adapted a plastic cylindrical conformer, in which is fixed the prepared teeth, the conformer provides a firm position into the steel device;

- Teeth were fixed in the cylinder with a fast-setting resin (Duracryl Plus), which has a low shrinkage factor and was shown to have elasticity similar to bone.
The study was conducted using a universal testing machine of the forces (Instron 4502). Over the system, forces were applied at an angle of 135 degrees from the long axis of the tooth, at a speed of $0.5 \mathrm{~mm} / \mathrm{min}$ until fracture occurred. The survey data were recorded using the computer software of the testing machine. Fracturing point has been highlighted in the load/displacement chart by recording a sudden change in load, indicating a resistance decrease of studied complex on applied load (Fig. 2). 


\section{Results}

The first statistical information relating to the characteristics of each sample refers to assessments of how these values are distributed and the evaluation of data distribution. Thereby next values were calculated: minimum, maximum, average and median applied force on samples and displacement of post under the force.

After statistical processing the experimental results indicators obtained were arranged in Fig. $3 a$ and $3 b$ expressing what is essential and common to all the units in groups $\mathrm{C}, \mathrm{G}$ and $\mathrm{S}$.

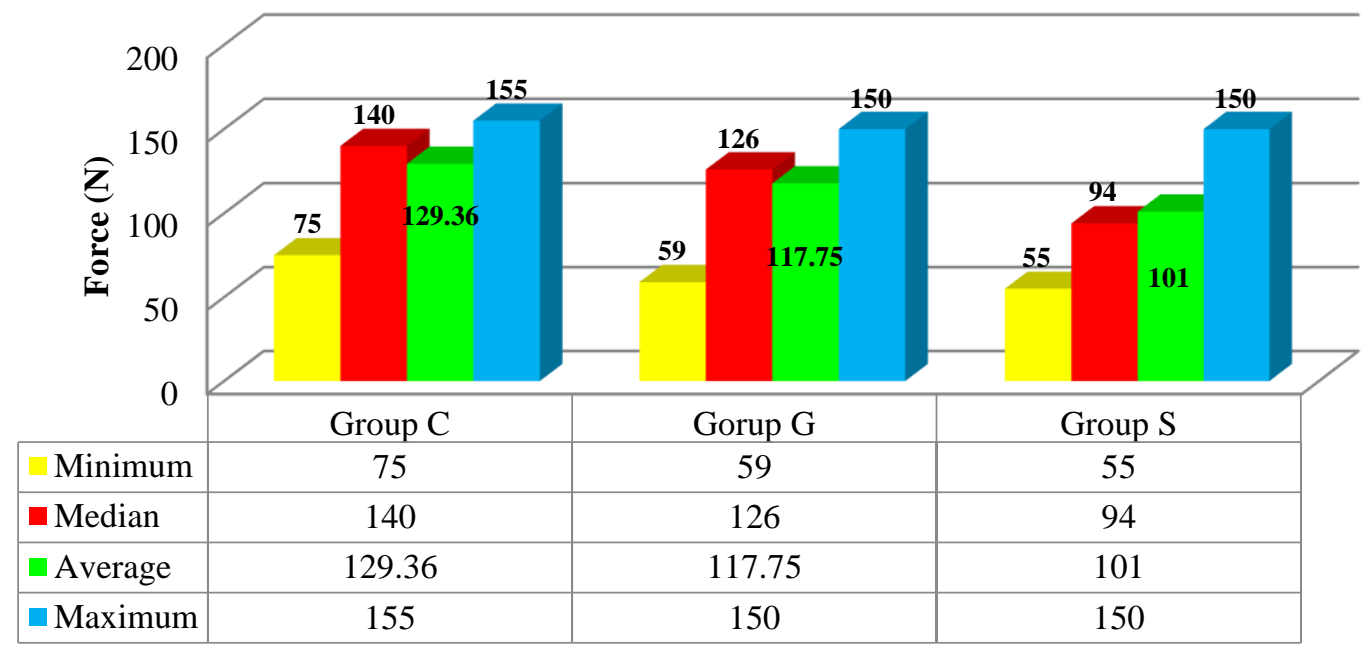

Figure 3a. Strength at which the samples failed

In conclusion, we obtained a significant decrease of the minimum force at which microscopic displacement phenomena occurred at the dentin-adhesive-post interface, recorded by the universal testing machine. Thus, at group $S$ level, minimum force was decreased by $26.67 \%$ and in the group $\mathrm{G}$ by only $21.33 \%$. Regarding central values of statistical series, respectively median, largest decreases was obtained in group S. Similarly, decreased values have been obtained for average and minor changes for maximum force at which is installed the displacement phenomenon.

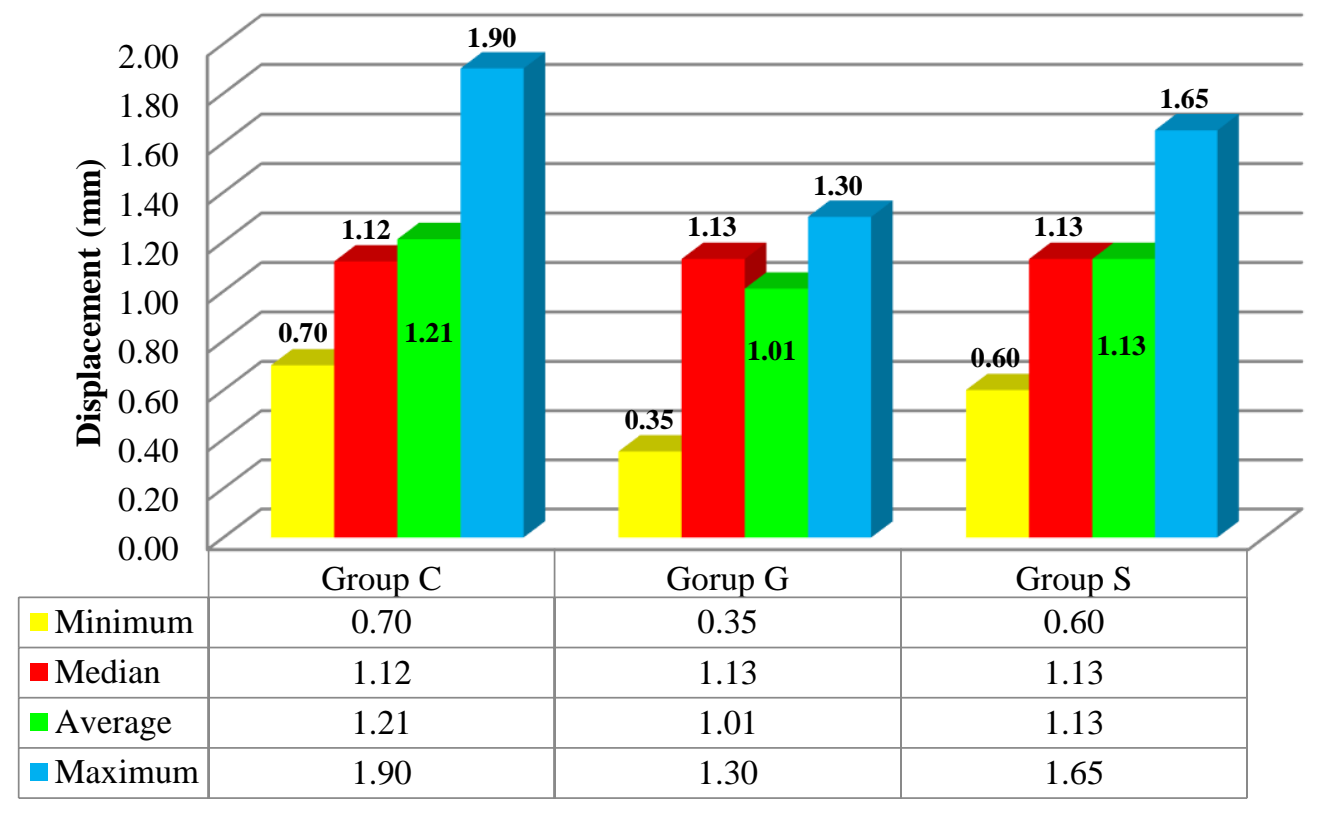

Figure 3b. Displacement at which the samples failed 
Table 1. Relative indicators force variation and posts displacement from experimental series groups $\mathrm{G}$ and $\mathrm{S}$ compared to the control group $\mathrm{C}$

\begin{tabular}{|c||c|c|c||c|c|c||}
\hline \multirow{2}{*}{$\begin{array}{c}\text { Statistical } \\
\text { indicators }\end{array}$} & \multicolumn{3}{c||}{ Force variation (\%) } & \multicolumn{3}{c||}{ Displacement variation (\%) } \\
\cline { 2 - 7 } & Group C & Group G & Group $S$ & Group C & Group G & Group $S$ \\
\hline \hline Minimum & 100 & $-21,33$ & $-26,67$ & 100 & $-100,00$ & $-14,29$ \\
\hline Median & 100 & $-10,00$ & $-32,86$ & 100 & $+0,89$ & $+0,89$ \\
\hline Average & 100 & $-8,97$ & $-21,92$ & 100 & $-16,53$ & $-7,92$ \\
\hline Maximum & 100 & $-3,23$ & $-3,23$ & 100 & $-31,58$ & $-13,16$ \\
\hline
\end{tabular}

Another aspect is the relationship between the post displacement in the field of elastic deformations and the force at which displacements appear. Thus, variations recorded in the group $\mathrm{G}$ were greater compared with the control group $\mathrm{C}$, in the sense that displacement occurred faster. It is noted that medians are relatively the same in this situation, for all groups.

From the statistical analysis point of view, individual values and the distribution of these values are both important. To assess values, Box-plot diagrams were used to provide information on central tendency and the shape of distribution of experimental studied values.

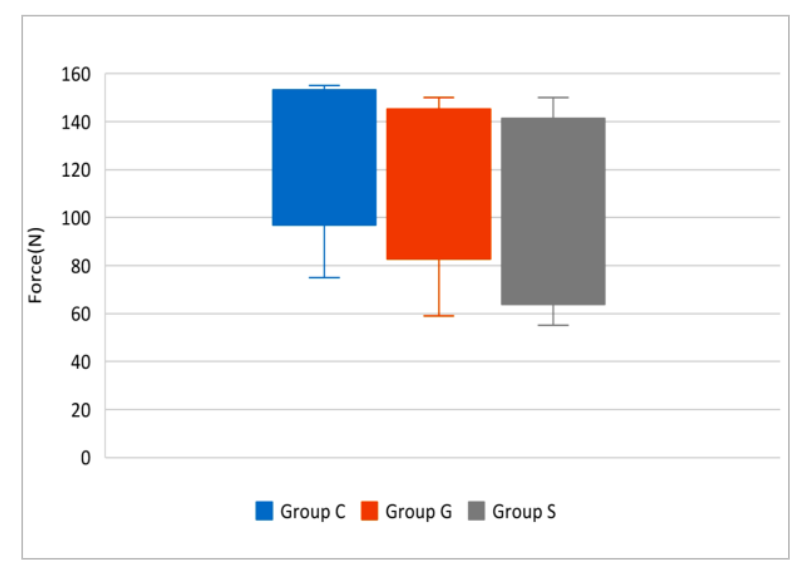

Figure 4. Box-plot diagram for forces

Concerning box plot diagram from Fig. 5 it is noted high data dispersion around the average of group $\mathrm{C}$, comparing to the other two. In addition, for the group $\mathrm{S}$ there is a symmetric concentration of $50 \%$ of the data around the median value. In group $\mathrm{G}$ we have a pronounced asymmetry, which is manifested through vicinity of most of the elements to the maximum displacement value.
Analyzing diagram of data dispersion in Fig. 4, it is observed that $50 \%$ of them are concentrated in the range of 3rd quartile (Q3) and 1st quartile (Q1). This area is defined by the blue rectangle and has a nearly identical distribution across groups $\mathrm{C}$ and $\mathrm{G}$ and nearly double for group $\mathrm{S}$. Group $\mathrm{C}$ and $\mathrm{G}$ series units have an asymmetric distribution, focusing on the peaks. The group $\mathrm{S}$ data shows a symmetrical distribution between maximum and minimum values. The median, marked by the horizontal line within each rectangle, divided into two values of each series. "T's" of each group marks the highest and lowest value obtained in the experimental data.

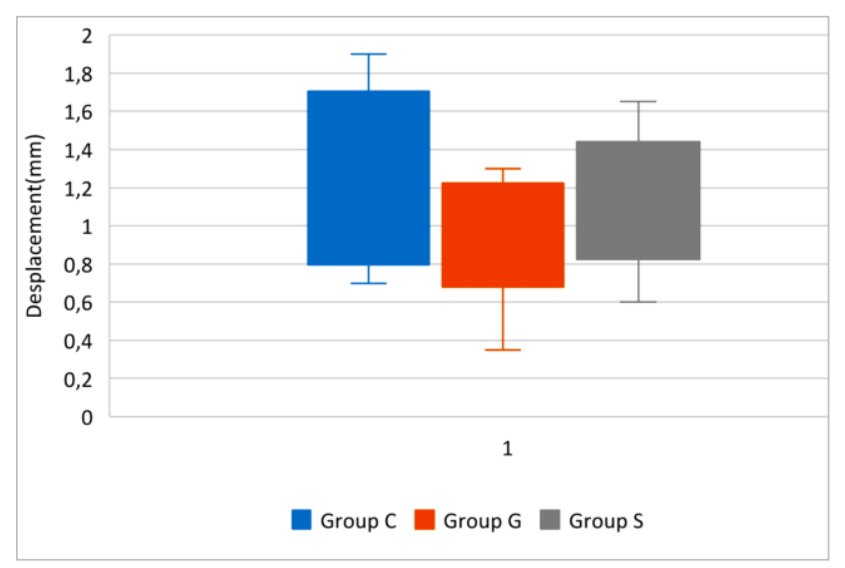

Figure 5. Box-plot diagram for displacement

Median of groups $\mathrm{G}$ and $\mathrm{S}$ have the same value, $1.13 \mathrm{~mm}$, value closed to median of group $\mathrm{C}$.

As a general trend, the level of forces and displacements corresponding to third series has an asymmetric distribution in group $\mathrm{G}$, towards the area of maximum values with small dispersion.

The analysis of Fig. 6 and Fig. 7 provides an overview of force and displacement averages. 


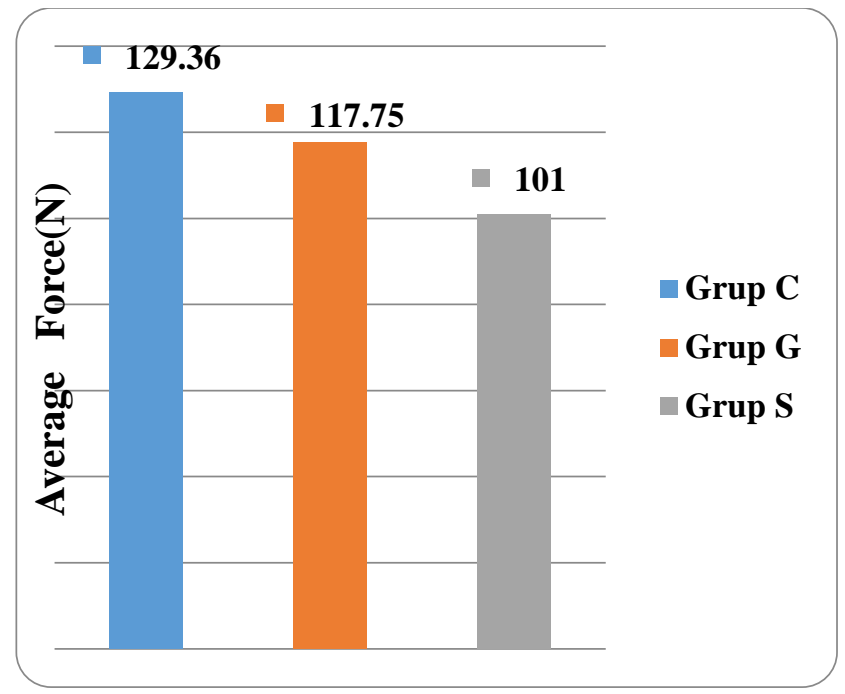

Figure 6. Average Force

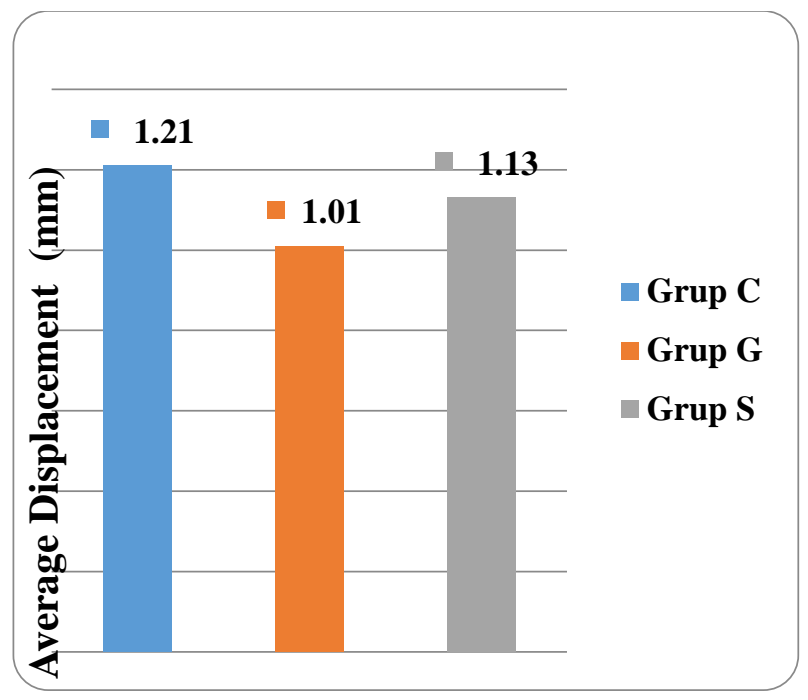

Figure 7. Average Displacement

Table 2. Synthetic indicators of dispersion for force

\begin{tabular}{|c|c|c|c|c|c|}
\hline Force & $\begin{array}{c}\text { Number of } \\
\text { samples }\end{array}$ & Average & $\begin{array}{c}\text { Standard } \\
\text { Deviation }(\sigma)\end{array}$ & $\begin{array}{c}\text { Standard error } \\
\left(\sigma_{\mathbf{m}}\right)\end{array}$ & $\begin{array}{c}\text { Variation } \\
\text { coefficient (v) } \\
\%\end{array}$ \\
\hline Group C & 8 & 134 & 32,310 & 11,423 & 24,11 \\
\hline Group G & 8 & 117,88 & 35,313 & 12,485 & 29,96 \\
\hline Group S & 8 & 109 & 37,394 & 15,919 & 34,31 \\
\hline Total & 24 & 120,29 & 35,451 & 7,236 & 29,47 \\
\hline
\end{tabular}

Based on the synthetic indicators of dispersion from Table 2, several considerations regarding the split of all the individual levels of force or displacement to their average level can be made, except that the values of variance (dispersion) are calculated in ANOVA tables. The distance between the given points of the experiment within one group and the average, are given by standard deviation. A reasonable confidence level of $95 \%$ was considered. This corresponds to two standard deviations above or below average. The remaining $5 \%$ of the results will have no statistical significance, being beyond the area of $2 \sigma$ without being consistent with the experimental model.
Calculated standard errors shows that the greatest accuracy in estimating the average was in group $\mathrm{C}$ and the lowest in group $\mathrm{S}$. As the number of experimental samples is higher, such as the total average of the groups, the fluctuation regarding its estimation is lower. This statement is supported by value $\sigma_{\mathrm{m}}=7.236$ for total arithmetic average.

The variation coefficient as a relative measure of dispersion can help us to complete the homogeneity image of the experimental results. As the dispersion is lower, the homogeneity is better and has a higher representativeness of the average.

Table 3. Force Analysis: ANOVA Single Factor

\begin{tabular}{|c|c|c|c|c|}
\hline \multicolumn{5}{|c|}{ SUMMARY } \\
\hline Groups & Count & Sum & Average & Variance \\
\hline Group C & 8 & 1035 & 129,375 & 899,9821 \\
\hline Group G & 8 & 942 & 117,75 & 1093,357 \\
\hline Group S & 8 & 808 & 101 & 1398,286 \\
\hline
\end{tabular}

\begin{tabular}{|l|c|c|c|c|c|c|}
\hline \multicolumn{7}{|c|}{ ANOVA } \\
\hline Source of Variation & $S S$ & $d f$ & $M S$ & $F$ & $P$-value & F crit \\
\hline Between Groups & 3255,5833 & 2 & 1627,79167 & 1,439833 & 0,259421 & 3,4668 \\
\hline Within Groups & 23741,375 & 21 & 1130,54167 & & & \\
\hline Total & $\mathbf{2 6 9 9 6 , 9 5 8}$ & $\mathbf{2 3}$ & & & & \\
\hline
\end{tabular}


Variation coefficients from Table 2 can be used as a significance test of average representativeness. As the values of these coefficients are in the range [24.11\% $34.31 \%$, it means that the force average is moderately representative. Analysis of displacement data is similar to that carried out on force.

Any differences between averages of force for three experimental groups are tested by applying ANOVA Single factor test analysis.

To decrease the impact of statistically significant values obtained by chance, it is considered a threshold of significance $\mathrm{p}=0.05$, which provide a confidence level of $95 \%$.
Analyzing the results in Table 3, it appears that $P$ value $>0.05$, and $F<F$ crit.

In conclusion, the null hypothesis is accepted, which means that, concerning the force, there is a significant difference between the three groups subject to the experiment for threshold of $95 \%$. Therefore, the average value of force at which the displacement phenomenon at the interfaces dentin-adhesive-post occur is not much influenced by the type of pretreatment of the experimental samples.

Further is done similarly to test any differences between averages of displacement with the same threshold of significance $\mathrm{p}=0.05$, obtaining data from Table 4 .

Table 4. Displacement analysis: ANOVA Single Factor

\begin{tabular}{|c|c|c|c|c|}
\hline \multicolumn{5}{|c|}{ SUMMARY } \\
\hline Groups & Count & Sum & Average & Variance \\
\hline Group C & 8 & 9,65 & 1,20625 & 0,176483929 \\
\hline Group G & 8 & 8,04 & 1,005 & 0,095342857 \\
\hline Group S & 8 & 9,05 & 1,13125 & 0,085441071 \\
\hline
\end{tabular}

\begin{tabular}{|c|c|c|c|c|c|c|}
\hline \multicolumn{7}{|c|}{ ANOVA } \\
\hline Source of Variation & $S S$ & $d f$ & $M S$ & $F$ & $P$-value & $F$ crit \\
\hline Between Groups & 0,165508 & 2 & 0,082754167 & 0,694891788 & 0,5102449 & 3,4668 \\
\hline Within Groups & 2,500875 & 21 & 0,119089286 & & & \\
\hline Total & 2,666383 & 23 & & & & \\
\hline
\end{tabular}

Table 4 identifies P-value $>0.05$, and $\mathrm{F}<\mathrm{F}$ crit. therefore the null hypothesis is accepted also in case of displacements. This leads to the conclusion that in case of displacement there is not a significant difference between the three groups submitted to experiment, for a threshold of $95 \%$.

Systematization of experimental data and calculation of average values showed that surface acid etching or sandblasting decreases the resistance of tooth-post system compared to control group.

Applying ANOVA test showed that displacement phenomena at interfaces dentin-adhesive-post is not significantly influenced by the type of surface treatment, acid etching or sandblasting, compared to control group.

\section{Discussions}

The present study involved the acid etching and sandblasting as pretreatments of the fiberglass posts. In the experimental group, in which the posts were acid engraved samples yielded at greater forces $(117.75 \mathrm{~N})$ compared to sandblasted posts group $(101 \mathrm{~N})$, showing that adhesive strengths was higher in case of the group with acid etching pretreatment. Also, the study included a control group, in which the posts have not been treated before lutting. At the time of displacement, the results showed values significantly different compared to the other groups, the control group average force is the $129.36 \mathrm{~N}$ - higher than the group with acid etching. Thus, we conclude that the control group showed the most significant adhesive strength.

Comparing the results of our experiment with previous studies, current experiment fit within similar parameters. The control group showed slightly increased adhesive strength values, compared with the groups were surface pretreatment was carried out, and acid engraved posts group presented values above those of the sandblasted posts group.

\section{Conclusions}

This study started from the assumption that the surface treatment of fiber glass posts, before adhesive lutting, will improved adhesive strength against displacement.

Statistical analysis performed through ANOVA test, revealed that displacement phenomena at interfaces dentinadhesive cement-post is not significantly influenced by the type of surface pretreatment, acid etching or sandblasting, compared control group. The control group showed slightly increased adhesive strength values, compared with the groups in which surface pretreatment was carried out, and 
the acid engraved posts group presented values above those of the group with sandblasted posts.

\section{Acknowledgement}

In this article, all the authors have equal contributions to the first author.

\section{References}

1. L.W. STOCKTON. Factors affecting retention of post systems: a literature review. J. Prosthet. Dent., 81, 380-5 (1999).

2. J.P. STANDLEE, A.A. CAPUTO, E.C. HANSON. Retention of endodontic dowels: effects of cement, dowel length, diameter, and design. J. Prosth. Dent., 39, 400-5 (1978).

3. I. NERGIZ, P. SCHMAGE, M. OZCAN, U. PLATZER. Effect of length and diameter of tapered posts on the retention. J. Oral. Rehabil., 29, 28-34 (2002).

4. B.I. COHEN, B.L. MUSIKANT, A.S. DEUTSCH. Comparison of retentive properties of four post systems. J. Prosthet. Dent., 68, 264-8 (1992).

5. B.I. COHEN, M.K. PAGNILLO, I. NEWMAN \& al, Retention of three endodontic posts cemented with five dental cements. J. Prosthet. Dent., 79, 520-5 (1998).

6. M. ROSIN, C. SPLIETH, M. WILKENS, G. MEYER. Effect of cement type on retention of a tapered post with a self-cutting double thread. J. Dent., 28, 577-82 (2000).

7. D.B. MENDOZA, W.S. EAKLE, E.A. KAHL, R. HO. Root reinforcement with a resinbonded preformed post. J. Prosthet. Dent., 78, 10-4 (1997).

8. A. BALBOSH, M. KERN. Effect of surface treatment on retention of glass-fiber endodontic posts; J. Prosthet. Dent., Volume 95 (3), 218-223 (2006).

9. Y. CHOI, A. PAE, E,J. PARK, R.F. WRIGHT. The effect of surface treatment of fiber-reinforced posts on adhesion of a resin-based luting agent; The J. Prosth. Dent., June, Volume 103 (6), 362-368 (2010).

10. G. SAHINKESEN, U. ERDEMIR, E.A. OKTAY, H.S. SANCAKLI. The effect of post surface silanization and luting agents on the push-out bond strengths of adhesively inserted fiber reinforced posts; Int. J. Adhesion \& Adhesives 31, 265-270 (2011).

11. J. PERDIGAÕ, G. GOMES, I.K. LEE. The effect of silane on the bond strengths of fiber posts; Dent. Mat. 22, $752-758$ (2006).

12. M. SUMITHA, R. KOTHANDARAMAN, M. SEKAR. Evaluation of post-surface conditioning to improve interfacial adhesion in post-core restorations; J. Conserv. Dent. Jan-Mar; 14(1), 28-31(2011).

13. P. SCHMAGE, F.Y. CAKIR, I. NERGIZ, P. PFEIFFER. Effect of surface conditioning on the retentive bond strengths of fiber reinforced composite posts; J. Prosthet. Dent., December, 102, 368-377 (2009).

14. A. SAHAFI, A. PEUTZFELDT, E. ASMUSSEN, K. GOTFREDSEN. Retention and Failure Morphology of Prefabricated Posts; Int. J. Prosthet. 17 (3), 307-311 (2004).

15. B. OHLMANN, F. FICKENSCHER, J. DREYHAUPT et al. The effect of two luting agents, pretreatment of the post, and pretreatment of the canal dentin on the retention of fiber-reinforced composite posts; J. Prosthet. Dent., 36, 87-92 (2008).

16. M. YENISEY, S. KULUNK. Effects of chemical surface treatments of quartz and glass fiber posts on the retention of a composite resin; J. Prosthet. Dent. January, Volume 99, Issue 1, 38-45 (2008)

17. S. ZAKEREYYA, M. GHAZAL, M. KERN. Effects of endodontic post surface treatment, dentin conditioning, and artificial aging on the retention of glass fiber-reinforced composite resin posts; J. Prosthet. Dent., Volume 103, 31-38 (2010).

18. G.M. GOMES, O.M.M. GOMES, A. REIS \& al. Regional Bond Strengths to Root Canal Dentin of Fiber Posts Luted with Three Cementation Systems; The Braz. Dent. J., 22(6), 460-467 (2011). 